\title{
Involuntary attentional shifts due to orientation differences
}

\author{
JULIAN S. JOSEPH and LANCE M. OPTICAN \\ Laboratory of Sensorimotor Research, National Eye Institute \\ National Institutes of Health, Bethesda, Maryland
}

\begin{abstract}
We tested the ability of orientation differences to cause involuntary shifts of visual attention and found that these attentional shifts can occur in response to an orientation "pop-out" display. Texturelike cue stimuli consisting of discrete oriented bars, with either uniform orientation or containing a noninformative orthogonally oriented bar, were presented for a variable duration. Subsequent to or partially coincident with the cue stimulus was the target display of a localization or two-interval forced-choice task, followed by a mask display. Naive subjects consistently showed greater accuracy in trials with the target at the location of the orthogonal orientation compared with trials with uniformly oriented bars, with only $100 \mathrm{msec}$ between the cue and mask onsets. Discriminating these orientations required a stimulus onset asynchrony (SOA) of 50-70 msec. The attentional facilitation is transient, in most cases absent, with a cue-mask SOA of $250 \mathrm{msec}$. These results suggest that the preattentive character of some texture discrimination tasks with SOAs of only $100 \mathrm{msec}$ is vitiated by the involuntary attentional shifts that are caused by orientation differences.
\end{abstract}

Most models of human visual performance include two important subsystems, a preattentive system and an attentional system (see, e.g., Neisser, 1967). The preattentive system is generally thought to be responsible for rapid texture discrimination (Braun \& Sagi, 1991; Julesz, 1984) and parallel search performance (Treisman \& Gelade, 1980). In contrast, serial search performance is generally ascribed to a scan of focal attention (Nakayama \& Silverman, 1986; Treisman \& Gelade, 1980; Wolfe, Cave, \& Franzel, 1989). The preattentive and attentional systems are thought to be coupled in the sense that output of preattentive processing can cause attentional shifts (i.e., changes in the spatial distribution of the processing capacity of the attentional system). This coupling is evidenced by the attentional shifts resulting from suprathreshold luminance flashes (Jonides \& Yantis, 1988; Krose \& Julesz, 1989; Maylor, 1985; Miller, 1989; Müller \& Rabbitt, 1989; Posner \& Cohen, 1984; Yantis \& Jonides, 1984). This link between the two systems is undoubtedly important for seeing in natural conditions, since conspicuous elements in the scene pull our attentional focus from one location to another. In order to study this coupling, we need to investigate the involuntary attentional shifts elicited by various salient features.

We thank P. Cavanagh, C. L. Colby, M. E. Goldberg, K. P. Purpura D. L. Robinson, and S. Yantis for helpful conversations, and J. W. McClurkin and K. Nakayama for their constructive comments on the manuscript. Some of the experiments reported here were first presented at the May 1993 meeting of the Association for Research in Vision and Ophthalmology (Joseph \& Optican, 1993b) and the November 1993 meeting of the Psychonomic Society (Joseph \& Optican, 1993a). Correspondence should be addressed to J. S. Joseph, Vision Sciences Laboratory, Department of Psychology, Harvard University, Cambridge, MA 02138 (e-mail: jsj@isr.harvard.edu).
Orientation differences are among the more salient feature gradients known, resulting in rapid discrimination (Bergen \& Julesz, 1983) as well as parallel search performance (Treisman, 1985); this has a well-known physiological correlate in the orientation selectivity of striate neurons (Hubel \& Wiesel, 1968). Orientation differences play an important role in figure-ground separation (Beck, 1966; Julesz \& Bergen, 1983) and are of interest in the study of texture segmentation more generally. It has previously been suggested that textural differences, or local feature gradients, attract visual attention (Julesz, 1984, 1986; Julesz \& Bergen, 1983; Koch \& Ullman, 1985). If this is the case, a local orientation difference should cause an attentional shift and enhance the visual processing of less salient aspects of the scene in that region of space. On the basis of this shift, we would predict that within the traditional masking paradigm used in many texture discrimination studies, the processing would not be purely preattentive at sufficiently long stimulus onset asynchronies (SOAs) between the texture and the mask. Eventually, involuntary reallocation of processing resources would begin to occur. One of the purposes of this research is to establish not only that such involuntary reallocation does indeed occur, but also to determine what SOAs are required for the vitiation of purely preattentive texture processing.

Motivated by the masking paradigms used for the study of texture discrimination, we conducted a series of experiments in which the stimuli were composed of an orientation difference display and a target display followed by a mask. A task demanding attentional resources involved a target that presented either subsequently to or concurrently with an orientation differ nce stimulus. The orientation difference contained no information relevant 
to the task at hand. It is in this sense that the observed attentional shifts in response to the orientation differences were "involuntary." It should be noted that Kahneman and Treisman (1984) suggested the additional criterion for automatic attentional capture that the stimulus in question ought to cause attentional shifts even if attention is initially focused away from it (the "intentionality criterion"). Several researchers have studied this stronger sense of an involuntary attentional shift using $100 \%$ invalid (informative) cue stimuli and informative precues to direct the top-down focusing of attention (e.g., Folk, Remington, \& Johnston, 1992; Remington, Johnston, \& Yantis, 1992; Yantis \& Jonides, 1990). In the present research, however, we avoided any information content in the orientation stimulus in order to reduce the effects of top-down influences. Our goal in this research, then, was to establish that orientation differences cause attentional shifts even when they are noninformative for the task at hand, and it is in this sense that we will term these attentional shifts "involuntary."

Although the experiments we present here are not visual search experiments, they can shed some light on what occurs during a parallel search task. Any attentional shifts participating in a visual search for a distinct orientation are driven by top-down (voluntary or "endogenous") influences, as the subject endeavors to locate the target, as well as bottom-up (involuntary, reflexive, or "exogenous") influences (i.e., any involuntary shifts of attention caused by the local orientation difference). There is evidence that automatic and controlled processes contributing to visual attention have distinctive dynamics (Nakayama \& Mackeben, 1989; Weichselgartner \& Sperling, 1987). To arrive at a conservative measure of the attentional shifts occurring during a parallel search, we approached the elimination of top-down influences by displaying an orientation "pop-out" stimulus whose location was statistically unrelated to the position of a subsequently presented target.

Numerous studies have explored the involuntary attentional shifts caused by other stimuli. Posner and Cohen (1984) and Müller and Rabbitt (1989) found evidence for attentional capture by luminance increases in alreadyvisible objects. Abrupt onsets are now well known for their exogenous cuing property (Jonides \& Yantis, 1988; Remington et al., 1992; Yantis \& Jonides, 1984, 1990). Miller (1989) found that abrupt offsets can also capture attention under certain conditions. This was confirmed by Theeuwes (1991b), who also found that abrupt onsets did not attract attention when attention was intentionally focused according to a central precue. There is evidence that the appearance of a new object is the underlying source of the reflexive orienting toward abrupt onsets (Yantis \& Hillstrom, 1994) and is a prerequisite for attentional capture by motion (Hillstrom \& Yantis, 1994). Pashler (1988) observed attentional capture by color singletons with targets defined by form, but found that other patterns of color discontinuities caused no significant effects. Folk et al. (1992) reported that color discontinu- ities could also capture attention under conditions in which the target was defined by color, but not if it was defined by abrupt onset, while abrupt onsets did not attract attention as measured by color-defined targets (but see Yantis, 1993) and the response (Folk, Remington, \& Johnston, 1993). However, Theeuwes (1991a) observed that irrelevant items of unique color distracted attention away from luminance-defined and form-defined targets (see also Theeuwes, 1992), as well as those defined by color. Items of unique luminance drew attention away from color-defined and also luminance-defined targets. More recently, Theeuwes (1994) has reported attentional capture by color during tasks in which the target was defined by abrupt onset. Attentional capture by apparent motion has been found by Folk, Remington, and Wright (1994) for targets defined by motion but not for those defined by color or abrupt onset.

Bacon and Egeth (1994) have suggested that Theeuwes' results (1994) may have been due to a "singleton detection mode" in which any salient singletons capture attention as probed by singleton targets. However, Yantis and Egeth (1994) observed no attentional capture due to highly salient motion-defined or color-defined singletons, with visual search targets that were singletons; the target, when present, was the only perfectly vertical bar in an array of randomly oriented items. Therefore, not every salient singleton captures attention, even when probed with singleton targets. The present experiments focused on attentional capture by orientation singletons, using singleton targets, with the aim of determining whether attention can be captured under these circumstances by this type of orientation difference.

Using cue durations in the range of 700 to $1,300 \mathrm{msec}$, Kwak and Egeth (1992) observed slowed reaction times at the cued location (inhibition-of-return) in response to various types of noninformative cues, including orientation differences. We included cue durations in this range to see if these effects would also occur within our paradigm. We also included intermediate cue durations for the purpose of measuring the duration of the effects we might find for brief cues, thus providing a test of the notion that visual attention can be separated into sustained and transient components, with bottom-up (involuntary) influences dominating the transient part (Nakayama \& Mackeben, 1989).

\section{EXPERIMENT 1 Cuing by Orientation Differences}

Texture segregation based on orientation has been studied using discrete oriented items (see, e.g., Bergen \& Julesz, 1983; Knierim \& Van Essen, 1992; Luschow \& Nothdurft, 1993; Treisman, 1985), which give a finite difference approximation to a gradient, as well as using continuous textures (see, e.g., Landy \& Bergen, 1991). For the sake of simplicity, we investigated the effects produced by a single discrete item that was distinguished from surrounding items by having an orthogonal orientation. This 
allowed us to make a start in determining whether textural differences can cause involuntary shifts of visual attention.

\section{Method}

Subjects. Fourteen naive subjects, ages 18 to 35 years, with normal or corrected-to-normal vision, participated. The subjects were paid for their participation.

Apparatus. The displays were presented on a noninterlaced NEC 3DS $60-\mathrm{Hz}$ monitor with $800 \times 600$ resolution and approximately 32.5 pixels $/ \mathrm{cm}$, controlled by a Number Nine GXi TIGA card in a PC. Stimuli were viewed binocularly from a distance of $57 \mathrm{~cm}$, with a chinrest and foreheadrest to constrain head movements.

Stimuli and Procedure. In the first experiment, we measured the effects of involuntary attentional shifts due to an orientation difference as a function of its duration and location. We presented a $7 \times 7$ array of oriented bars (Figure $1 \mathrm{~A}$ ) of variable duration followed by a 50 -msec probe flash containing an $L$ surrounded by $T \mathrm{~s}$ (Figure 1B). The probe flash was immediately followed by a mask consisting of the union of the $L$ and the $T$. An overview of the presentation sequence in one trial is shown in Figure 2. The subject's task was to locate the target $L$ at one of four possible locations, shown in Figure 3. The orthogonal orientation cue contained no information about the target location and was useless for task performance. (We use the term cue more generally to refer to the display of oriented bars, whether it contains an oddball or not, despite the fact that it contains no information relevant to the task.) The cue stimulus contained an orientation oddball at one of the four possible target locations on $80 \%$ of the trials (cued trials). On the rest of the trials, all the bars of the cue stimulus were of uniform orientation (uncued trials). At the beginning of the first session, the subjects were presented with demonstration trials in which each stimulus frame was frozen, with the target in each one of its four possible locations (circled in Figure 3).

We aimed for an experimental design that measured the effects of the orientation difference without confounding luminance or contrast adaptation effects. For this reason, the bars were preceded by squares with the same number of pixels as the bars at the same luminance, centered at the same positions. The total presentation time for the squares plùs the bars was fixed at $1,000 \mathrm{msec}$. Thus, any luminance or contrast adaptation of early spatial filters had occurred for the same period of time when the probe appeared. This allowed the accuracy differences between cued and uncued trials to be compared more meaningfully across different cue durations.

The subjects initiated a trial by pressing a mouse button, at which time a fixation cross appeared in the center of the screen and remained throughout the trial for the purpose of preventing express saccades (Fischer \& Boch, 1983). After the cross had been present alone for $500 \mathrm{msec}$, the squares appeared on the display. Eye movements were not monitored; the cuing effects we observed were too rapid $(<100-\mathrm{msec} \mathrm{SOA})$ to have been due to eye movements away from the fixation cross. The subjects were instructed to fixate on the cross until the mask appeared, at which time they indicated the perceived target location by sliding and pressing a mouse. (The mouse arrow did not appear until after the mask had appeared and the mouse had been moved.) Upon the selection of a location, the screen cleared to the background gray level, and a beep was sounded if the selection was correct. At the beginning of each session, the subjects were informed that the distinctly oriented bar (if present) was unrelated to the location of the target $L$. The luminance of all stimuli was $90 \mathrm{~cd} / \mathrm{m}^{2}$, with a background luminance of $30 \mathrm{~cd} / \mathrm{m}^{2}$. The spacing in the stimulus arrays was $1.4^{\circ}$ between the centers of neighboring elements. The target locations were centered at an eccentricity of $3.9^{\circ}$. The squares were $14.8^{\prime}$ in size, the bars $7.4^{\prime} \times$ $30^{\prime}$, the lines composing the $L s$ and $T \mathrm{~s}$ were $7.4^{\prime} \times 18.5^{\prime}$, and the crosshairs were $3.7^{\prime} \times 14.8^{\prime}$. The squares and bars were placed with equal center-of-mass locations. The center of mass of a stim- ulus was calculated by assigning no weight to points at the background luminance and assigning some arbitrary weight to points at the stimulus luminance. The $T \mathrm{~s}$ were placed with center of mass as close as possible to that of the squares and bars in order to reduce the percept of motion in the transition. The $L$ was placed flush with the rows and columns defined by the $T \mathrm{~s}$ in order to keep the probe task difficult.

A summary of the frame sequence in each trial is as follows: (1) The fixation cross was presented alone for $500 \mathrm{msec}$ and stayed on until the selection was made. (2) Squares were presented for a duration of $1,000 \mathrm{msec}-t$, where $t$ was the cue stimulus duration on that trial. (3) The cue stimulus (display of oriented bars) was presented for a variable duration $t$. (4) The probe flash consisting of one $L$ in a field of $T \mathrm{~s}$ was presented for $50 \mathrm{msec}$. (5) The mask was presented until the selection was made.

S1-S6 were presented with cue durations of 100,250 , and $800 \mathrm{msec}$, each performing a total of 1,200 trials over two sessions. Thus, 80 trials were performed by each subject per cue duration (3) per condition (4) (necessarily twice as many for the near-invalid condition). S7-S8 performed the same number of trials and ses-

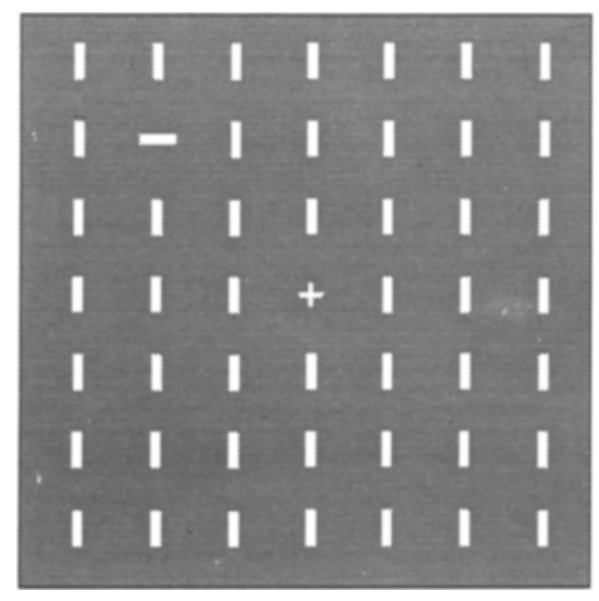

cue stimulus

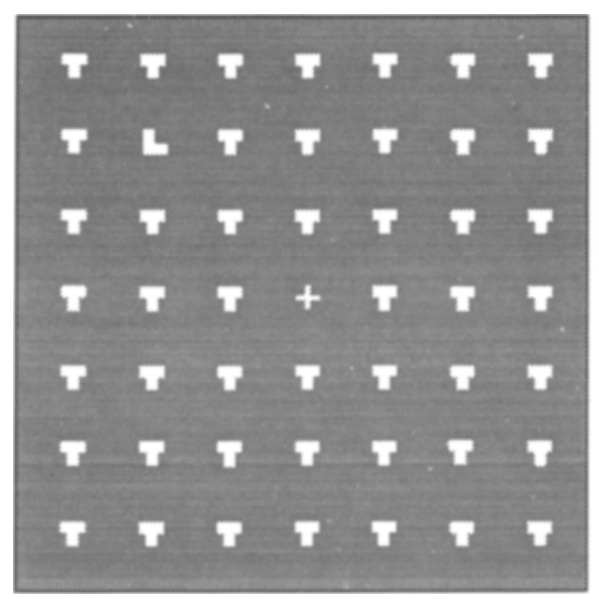

probe

(b)
Figure 1. Examples of the cue stimulus, which may or may not contain an orientation oddball, and the probe stimulus, which contains an $L$ in a field of $T$ s. The stimuli shown in this example would appear in a valid trial, in which the target $L$ appears at the same location as the orientation oddball. Of the trials that contain an oddball, $25 \%$ were of this type. The rest were invalid trials, in which the locations of the oddball and target were different. In all displays, the luminance of the background was $30 \mathrm{~cd} / \mathrm{m}^{2}$. White in the figures represents a luminance value of $90 \mathrm{~cd} / \mathrm{m}^{2}$. 


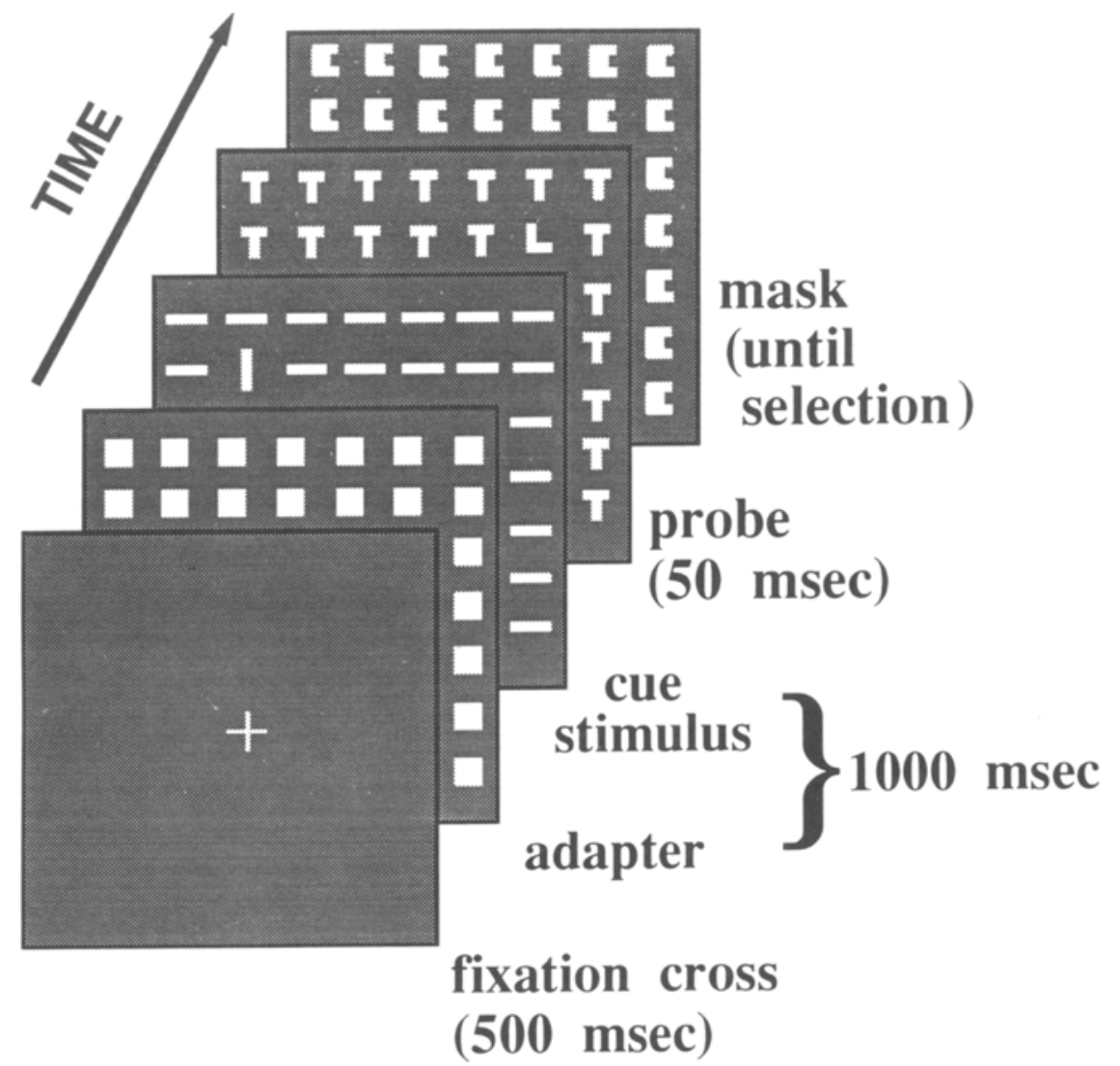

Figure 2. Overview of a trial in Experiment 1. The fixation cross alone appeared for $\mathbf{5 0 0}$ msec and remained throughout the trial. The squares played the role of an adapter for the luminance and contrast changes that occurred when the oriented bars we used were displayed abruptly. The cue stimulus (oriented bars) then appeared. The durations of the adapter and cue totaled $1,000 \mathrm{msec}$ on each trial, but the cue duration itself varied from trial to trial. The probe stimulus ( $L-T$ display) lasted $50 \mathrm{msec}$. This was followed by a union mask, which remained on display until subjects made their selection.

sions, but were presented with cue durations of 50,250 , and 500 msec. Finally, S9-S 14 were presented with cue durations of $50,100,250$, and $800 \mathrm{msec}$. They each performed three sessions totaling 1,920 trials, giving 96 trials per cue duration (4) per condition (4) (192 for near-invalid).

The sessions were held on separate days and lasted approximately 80 min each. Each subject was given 50 practice trials before the first session. Within each session, trials were balanced for background bar orientation (horizontal or vertical), target location, location of the orientation difference (if present), and cue duration, and they were randomly shuffled.

\section{Results}

Terminology used in discussing the data is defined in Figure 3, which illustrates the possible target locations relative to the orientation difference. The location of the orthogonal orientation is the pop-out (or valid) location, while the other possible target locations are the nearinvalid and far-invalid locations, in accordance with their respective proximities to the pop-out cue. Trials with uniformly oriented bars are the null-cue condition. The observed accuracies in the valid, null-cue, near-invalid, and far-invalid are plotted in Figure 4. The chance level of $25 \%$ is shown by the dashed line.
To determine the significance level of the observed within-subject accuracy difference between each cued condition and the null-cue condition, we performed the Fisher exact test (Brownlee, 1965; Fisher, 1935). ${ }^{1}$ In the bar graphs representing the data, an asterisk $\left({ }^{*}\right)$ denotes a difference from the null-cue condition with a significance level of $p<.05$. Error bars are plotted to aid inspection, as the standard error $[f(1-f) / N]^{1 / 2}$, where $f$ is the observed fraction correct and $N$ is the number of trials. Trials in which the subject selected an impossible location, that is, a location that was not one of the four possible target locations, were omitted from the analysis. Such trials constituted less than $0.4 \%$ of the trials in all experiments and all subjects, with no individual subject making more than $0.8 \%$ of this type of error. We attribute these errors to accidental buttonpresses while the mouse was being moved toward the location of the intended selection.

Each of the 8 subjects presented with 50 -msec cues showed facilitation at the pop-out location relative to the near-invalid location at the $p<.05$ level. All 8 also showed greater performance in valid trials compared with their performance in far-invalid trials. Of these 8 subjects, 7 showed improved performance in trials with a valid pop- 


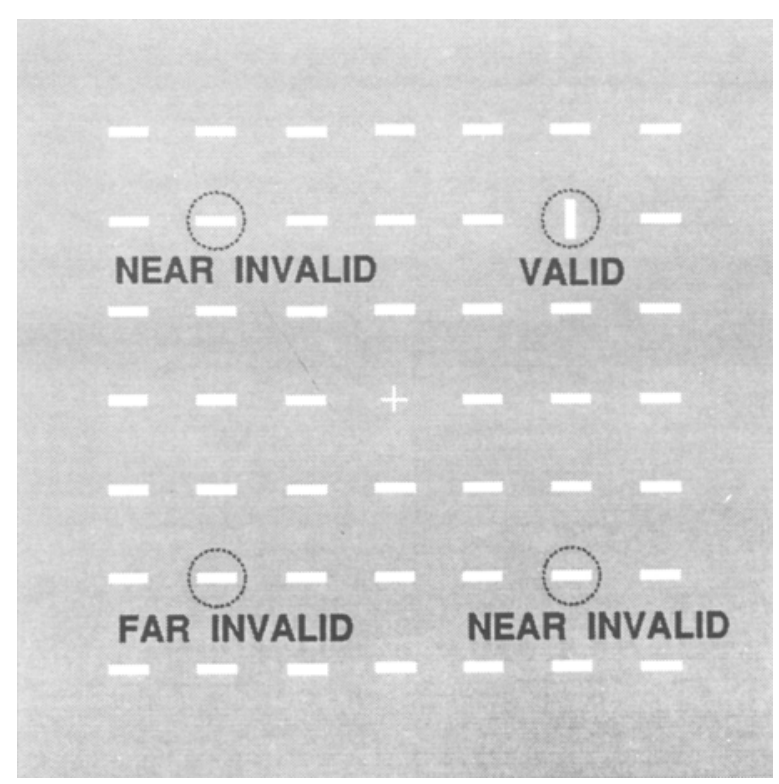

Figure 3. An example of the cue stimulus with the four possible target locations indicated. The target was equally likely to appear in each of these four locations. A valid trial had the target at the pop-out location. The invalid trials were subdivided into near-invalid and farinvalid trials, according to the proximity of the target to the pop-out. The dotted lines were not present in the actual stimulus. The possible target locations were at $3.9^{\circ}$ eccentricity.

out relative to their performance in the null-cue condition (no pop-out). The only exception to this, S14, showed the effect with $p<.056$. The attentional shifts can therefore be observed when the cue-mask SOA is only $100 \mathrm{msec}$ long. Evidence for attentional shifts in response to an orientation difference can also be obtained by observing the degraded performance at invalid locations. Performance decrements at locations other than the pop-out were to be expected in the event of an attentional shift toward the pop-out location. Of the 8 subjects presented with 50-msec cues, 6 showed poorer performance at near-invalid locations compared with performance in trials without pop-out.

For the 100 -msec cue duration, 12 out of 12 subjects showed greater pop-out facilitation compared to their performance in the null-cue condition. The cuing effects at later times were quite different, however. For $250-\mathrm{msec}$ cues, only 5 of 14 subjects showed pop-out facilitation; 3 showed inhibited performance. Thus, for longer popout durations, the effectiveness of an orientation pop-out cue often dissipated over time. This transient quality is consistent with the hypothesis of a transient component of attention to bottom-up processes (Nakayama \& Mackeben, 1989). One of the 2 subjects presented with 500msec cues showed inhibited performance. None of the 12 subjects showed facilitatory effects for 800 -msec cue durations, and 3 showed inhibition. The complete absence of facilitatory effects for $800-\mathrm{msec}$ cue stimuli demonstrates that the cuing effects at the shorter cue du- rations were not due to attentional capture by any cue in the transition from the oriented bars to the target stimulus. If some cue in that transition were responsible for the early cuing effects we observed, they would be present in the same strength even for very long bar durations. By the same reasoning, the effects at the shorter cue durations cannot have been due to display-display interactions between the cue and probe. Otherwise, such interactions would have caused an effect in the trials with 800 -msec cues. The observation of inhibited performance at the valid location relative to invalid locations or the null-cue condition for the longer cue durations within some subjects corroborates Kwak and Egeth's (1992) observation of Posner and Cohen's (1984) "inhibition-ofreturn" for 700-1,300-msec SOAs.

The cuing effects seen repeatedly at the 50- and 100msec cue durations could arguably have been due to a bias in favor of selecting the cued location. That this is not the case can be verified by looking at the selections made on invalidly cued trials with incorrect responses. These are trials in which the cue and target locations were different, and a nontarget location was selected. One of the three nontarget locations was the cued location, while the other two were uncued. A selection bias should then be revealed by a tendency to select the cued location on incorrect invalidly cued trials at a frequency greater than the chance level of $33 \%$. We find no such tendency. At the 50-msec cue duration, the cued location was selected with a frequency of $30 \%$, which is not significantly different from chance $[t(7)=1.31, p>.1]$. Similarly, at the 100-, 250-, and 800-msec cue durations, respectively, the proportions with which the cued location was selected were $28 \%[t(11)=1.76, p>.1], 36 \%$ $[t(13)=1.11, p>.1]$, and $35 \%[t(11)=0.73, p>.1]$. Therefore, there was no selection bias favoring the cued location. Hence, selection bias can be ruled out as an explanation for the cuing effects that we have reported. We addressed this issue more directly in Experiment 4 by means of a two-interval forced-choice paradigm.

\section{EXPERIMENT 2 \\ The Cuing Effects Occur Without the Contrast-Adapting Stimulus}

In the preceding experiment, we presented an array of squares before the oriented bars so that there was no change in the light level or the contrast of the display when the bars appeared. Each square was centered at the same position as the bar that would replace it, so there was no first-order motion signal in the transition from squares to bars. However, the second spatial moments of the square were different from those of the bar, and the change in these moments during the transition differed between the pop-out location and other locations. It is at least conceivable that the transition from squares to bars in Experiment 1, rather than the orientation difference itself, contained some cue that was responsible for the observed effects. While this contrast-adapting stimulus 

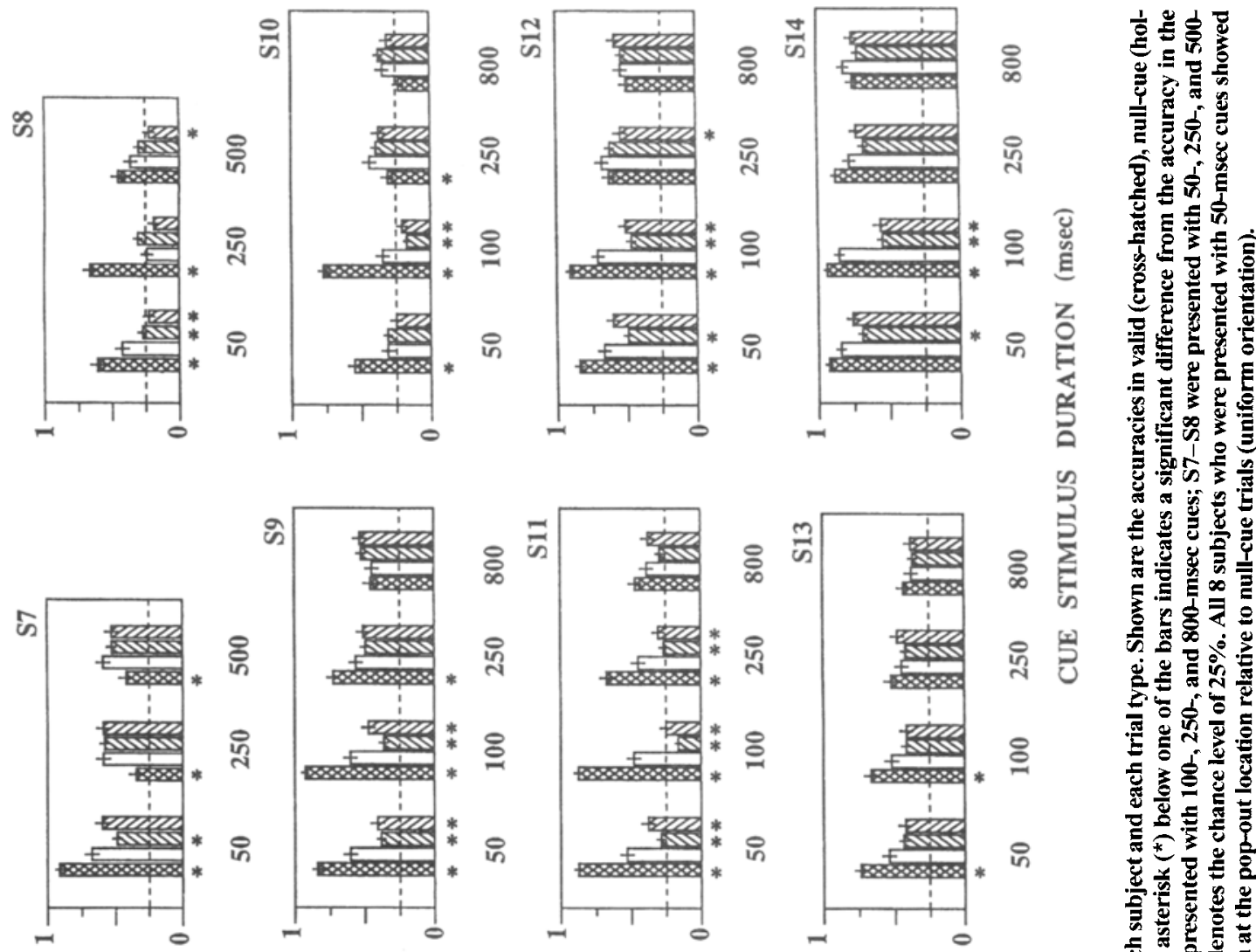

50

का

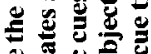

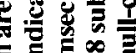

表定

故

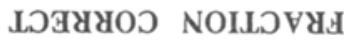

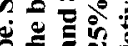

든

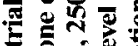

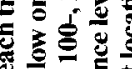

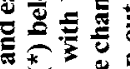

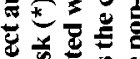

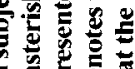

का

焉

to

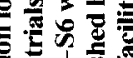

\%

农旁旁
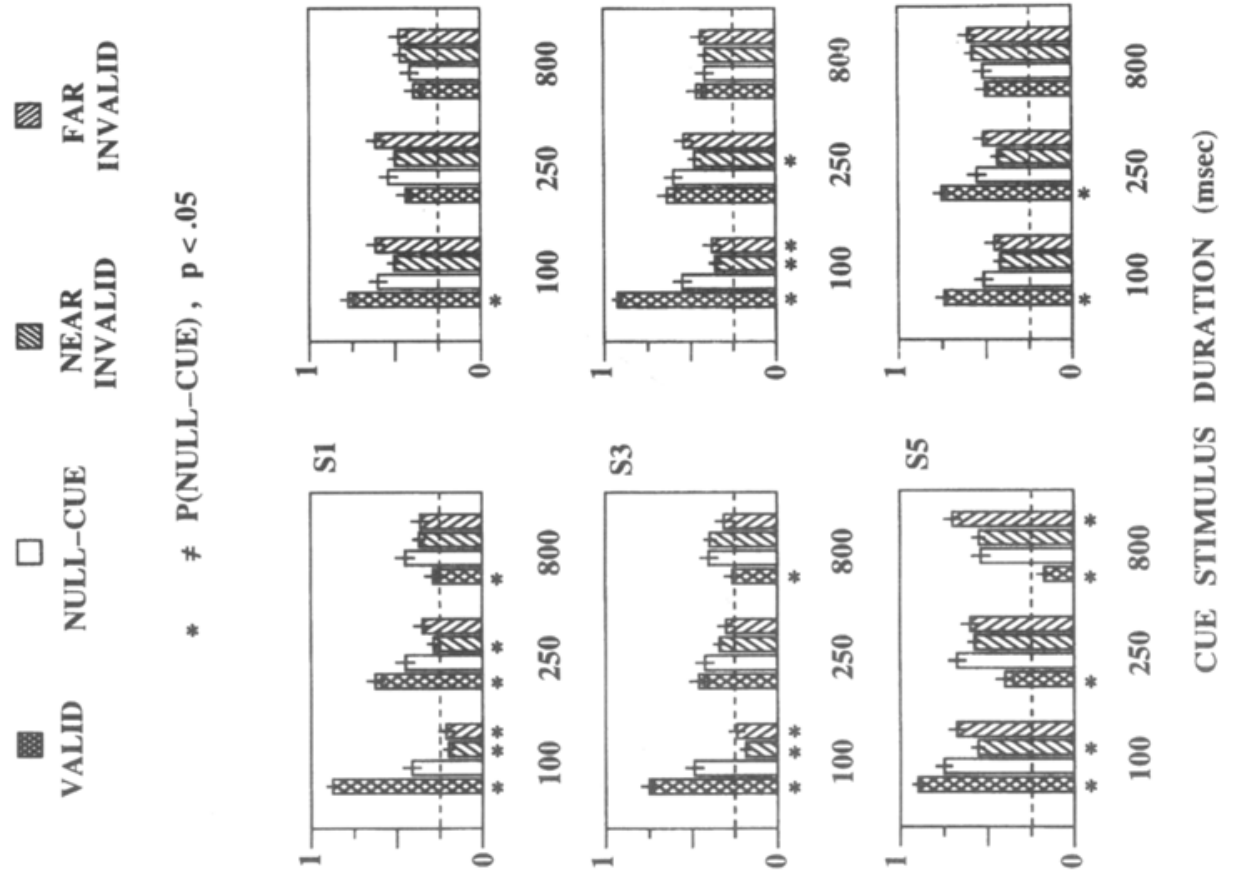

言害

踣

跣

言解

공

就它

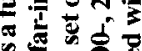

呵

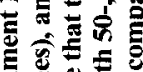

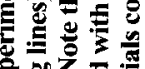

可㱐

돟

옹

谭

包导吉

중

है है

踏 
eliminates adaptation and gain control effects from the performance dynamics, it is not required in order to measure the effects of attention at any one time. As a control, then, we repeated Experiment 1 without the contrastadapting squares. We emphasize that an accuracy difference between conditions at a given cue duration continues to indicate that an attentional shift has occurred in response to that cue.

\section{Method}

Subjects. Two new naive subjects and one of the authors (J.S.J.) participated.

Stimuli and Procedure. The stimuli and procedure were the same as those in Experiment 1, except that no contrast-adapting squares were presented before the orientation stimulus. Each subject was presented with cue durations of $50,100,250$, and $800 \mathrm{msec}$. Each performed in two sessions for a total of 1,280 trials, yielding 64 trials per cue duration per condition (128 for near-invalid).

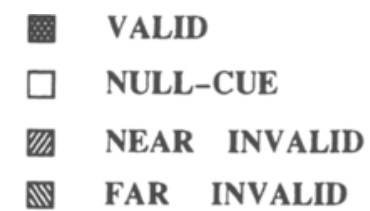

* $\quad \neq \mathrm{P}($ NULL-CUE $), \quad \mathrm{p}<.05$
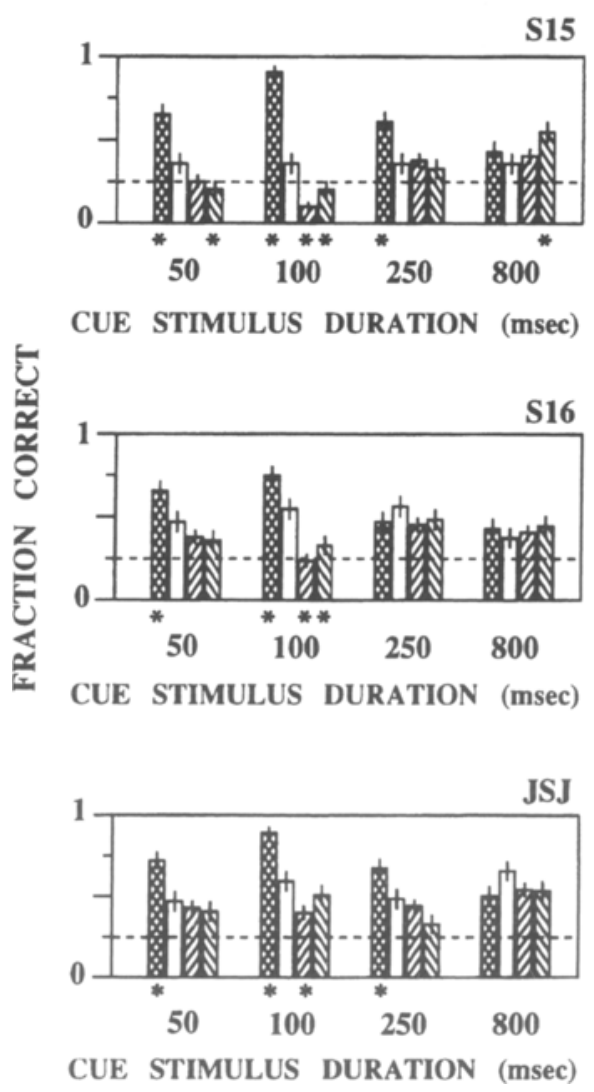

Figure 5. Results of Experiment 2. For 50-msec and 100-msec cues, all 3 subjects showed facilitation at the pop-out location relative to null-cue as well as near-invalid trials $(p<.05)$.

\section{Results}

The results are shown in Figure 5. All 3 subjects showed significantly greater accuracy $(p<.05)$ in validly cued trials than in the trials without pop-out for 50- and 100 msec cue durations. For both of these cue durations, each subject also showed greater performance in valid trials compared to both near-invalid and far-invalid trials. Thus, the cuing effects seen for short cue durations in Experiment 1 were not an artifact of the squares used in that experiment. As in Experiment 1, none of the subjects showed facilitation at the $800-\mathrm{msec}$ cue duration.

\section{EXPERIMENT 3 \\ The Cuing Effects Occur With a Different Probe Task}

To ensure that these cuing effects of an orientation difference were not peculiar to the type of probe we used in the first two experiments, we repeated Experiment 2 with a very different target. An overview of one of these trials is shown in Figure 6.

\section{Method}

Stimuli and Procedure. In the last videoframe of the bars, there was a dark square centered on one of the four possible target positions. The square was 8 pixels on each side and had a luminance of $4 \mathrm{~cd} / \mathrm{m}^{2}$. This was followed by a $100-\mathrm{msec}$ white-noise mask consisting of checks 4 pixels on a side with luminances of 90 and $4 \mathrm{~cd} / \mathrm{m}^{2}$. The mask region completely covered the region occupied by the bars. After the mask there appeared an array of selection tokens consisting of square outlines centered at each of the bar positions. The tokens remained until the subject selected one. We included a selection token at each array location as a check on whether the subjects understood which were possible target locations. The rate of selecting impossible locations was less than $0.4 \%$. In all other respects, the procedure was exactly the same as that in Experiment 2. Because the target luminance decrement had a presentation time of only $17 \mathrm{msec}$, subject performance in this task was substantially less than perfect, making this task a useful probe for visual attention.

We emphasize that because the target was presented simultaneously with the last videoframe of the cue, this paradigm gives a stricter measure of the SOAs for which the effects of attentional shifts occur. In Experiments 1 and 2 we had to add the target duration of $50 \mathrm{msec}$ to the cue duration in conservatively determining this. That was not necessary in Experiment 3, however, because the cue duration included the presentation of the probe stimulus, so this duration alone was the SOA of interest.

Subjects. Two new naive subjects and one author (J.S.J.) participated.

\section{Results}

The results for Experiment 3 are shown in Figure 7. All subjects showed facilitation at the pop-out location for 100-msec cue durations, compared with the null-cue, near-invalid, and far-invalid conditions $(p<.05)$. Because the target here was presented together with the last videoframe of the cue, we concluded that cuing effects of the orientation pop-out occurred with a 100 -msec SOA. These results confirm the existence of involuntary attentional shifts due to orientation differences, as measured by a very different probe target. Furthermore, with 


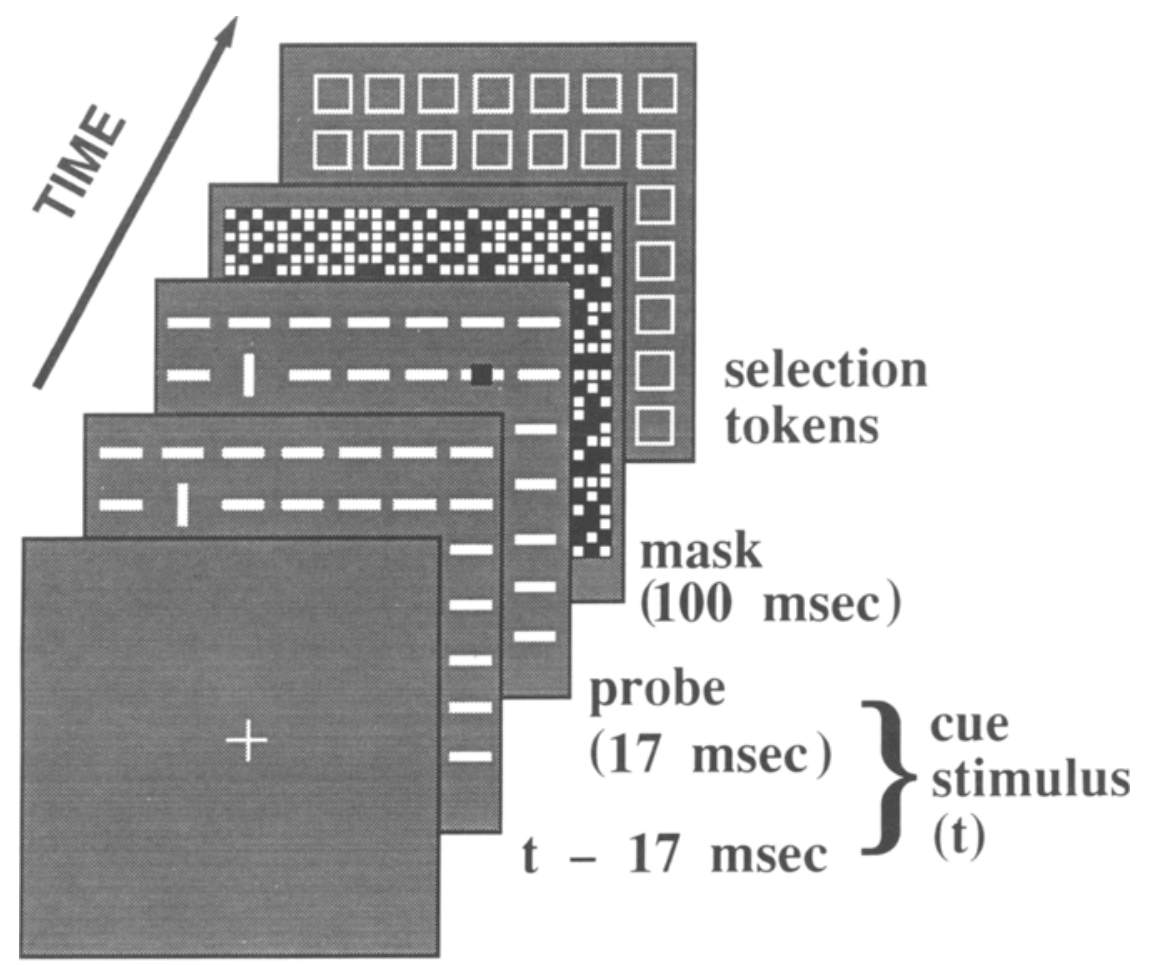

\title{
fixation cross (500 msec)
}

\begin{abstract}
Figure 6. Overview of a trial in Experiment 3. The fixation cross appeared alone for $500 \mathrm{msec}$ and remained until the selection was made. The cue stimulus appeared for a time chosen randomly from among 50, 100, 250, or $800 \mathrm{msec}$. On the last videoframe of this cue presentation, of $17 \mathrm{msec}$ duration, was a dark square target centered on one of the four possible target locations. This was immediately followed by a 100-msec white-noise mask and a display of square-framed tokens used by the subjects to make their selections of the target location. Black in the figure represents a luminance of $4 \mathrm{~cd} / \mathrm{m}^{2}$.
\end{abstract}

the 50-msec SOA, S17 showed pop-out facilitation relative to null-cue trials at the $p<.055$ level, and J.S.J. at the $p<.07$ level. These results suggest that the rate of appearance of these cuing effects is subject to individual differences and can in some cases produce attentional shifts with only a 50 -msec SOA. All subjects tested showed cuing effects within $100 \mathrm{msec}$, however. As in Experiments 1 and 2, no facilitation was seen at the $800-\mathrm{msec}$ SOA.

\section{EXPERIMENT 4 \\ The Cuing Effects Are Not Due to a Selection Bias}

The pop-out facilitation observed for brief cue durations is unlikely to have been due to a bias on the part of the subjects toward selecting the pop-out location. An analysis of incorrect invalidly cued trials revealed no significant bias for selecting the cued location more frequently than at chance level. This absence of a selection bias is not surprising, given that the subjects had been informed that the target location was unrelated to the location of any uniquely oriented item, and this fact was confirmed by their experience during the trials. However, to make sure that the cuing effects still occur even when a selection bias is impossible even in principle, we ran 2 new naive subjects and one author (J.S.J.) in a two-interval forced-choice paradigm (Krose \& Julesz, 1989; Sperling \& Dosher, 1986). Two sequences of stimuli were presented, separated by a 500 -msec blank interval. The two sequences were identical, except that one contained the targquence contained the target by pressing one of two et. The subject's task was to indicate which sequence contained the target by pressing one of two mouse buttons. Figure 8 illustrates the two sequences that appeared in one trial; in the example depicted, the target appears in the first sequence.

\section{Method}

In each sequence, a fixation cross appeared in the center of the screen and remained through the masking stimulus. After $500 \mathrm{msec}$ of the fixation cross alone, the cue stimulus was presented for either 50 or $100 \mathrm{msec}$. In the last two frames of this presentation $(33 \mathrm{msec}$ ), the target appeared (if this was the sequence containing the target). The target was a square break in the center of one of the bars, 4 pixels on a side (the width of the bars), at the background luminance level. As in Experiments 1-3, this target was equally 
VALID

NULL-CUE

NEAR INVALID

FAR INVALID

$* \quad \neq \mathrm{P}($ NULL-CUE),$\quad \mathrm{p}<.05$

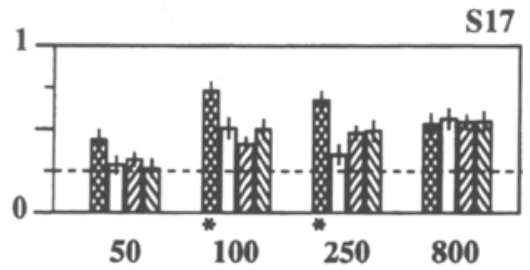

CUE STIMULUS DURATION (msec)
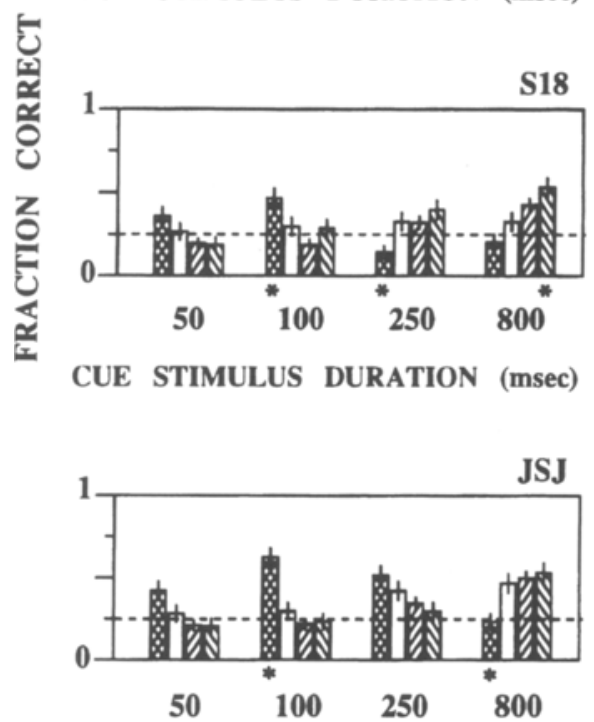

CUE STIMULUS DURATION (msec)

Figure 7. Results of Experiment 3. For 100-msec asynchrony between the cue stimulus and the mask, all 3 subjects showed facilitation at the pop-out location relative to null-cue trials as well as nearinvalid trials and far-invalid trials. For 50-msec cues, performance was greater in valid-cue than in the null-cue trials for S17 $(p<.055)$ and for J.S.J. $(p<.07)$. It is important to emphasize that, because the probe appeared on the last videoframe of the cue, the cue duration equals the cue-mask stimulus onset asynchrony (SOA). Thus, attention effects are seen with an SOA of only 100 msec.

likely to appear in each of the same four possible locations independently of the appearance of the bars. The target was equally likely to appear in either the first or second sequence. It was immediately followed by a 100 -msec white-noise mask consisting of checks 4 pixels on a side with luminance levels of $90 \mathrm{~cd} / \mathrm{m}^{2}$ and $30 \mathrm{~cd} / \mathrm{m}^{2}$, covering the region occupied by the bars.

We also used this experiment as an opportunity to explore the effects of competing orientation differences in the display. Given what is known about the limited processing capacity of visual attention (Eriksen \& St. James, 1986; Eriksen \& Yeh, 1985), one might suspect that performance would be poorer when there are multiple cues competing for attentional resources than with a single cue. We tested this assertion by including trials with four ori- entation oddballs, one at each possible target location. This allcued condition was presented with the same cue durations as the other trials and was randomly interleaved with them.

The subjects were given demonstration trials in which the stimuli were frozen, with the target in each position and each sequence. They were then given 50 practice trials, followed by 1,152 trials in two sessions (96 trials per cue duration per cue condition). The trials in each session were balanced for cue duration, target sequence, and cue condition, and they were randomly shuffled.

\section{Results}

The results are shown in Figure 9. All 3 subjects showed pop-out facilitation relative to the null-cue condition for $100-$ msec cues $(p<.05)$, confirming that the observations of pop-out facilitation for a $100-\mathrm{msec}$ SOA in Experiments 1-3 were not due to a selection bias. These attentional shifts produced substantial performance differences between the valid-cue and null-cue circumstances. These differences cannot have been due to inhibition-of-return caused by the first sequence, since that would not have resulted in enhanced performance. We note that none of the subjects showed facilitation for 50-msec cues, indicating that the cuing effects become detectable and indeed strong at SOAs between 50 and $100 \mathrm{msec}$. In each subject, the performance in all-cued trials was significantly lower than in the valid-cue trials $(p<.05)$. This means that multiple orientation cues do in fact compete for processing resources, as expected for a limited attentional capacity.

\section{EXPERIMENT 5 Rapid Discrimination and Localization}

To demonstrate that our orientation stimulus is a reasonable one from the point of view of traditional studies of texture discrimination, we measured the orientation discrimination performance with the same stimuli at a variety of SOAs. This permitted comparison with the SOAs that are known from the literature to be expected for this type of discrimination task.

\section{Method}

Design. We used a design that keeps the conditions close to those of the pop-out cuing experiments. The orientation difference stimuli used in this experiment were precisely the same as those in Experiments 1-4, and all subjects had participated in those experiments as well. For subjects who had participated in Experiment 1, the oriented bars were preceded by squares of the same number of pixels and the same luminance as in that experiment, with the total duration of the squares plus the bars fixed at 1,000 msec. Subjects who had participated in Experiments 2 and 3 were not presented with these adapting squares. The four possible locations of the pop-out were also the same. The task required subjects to attend to the same four locations as those in Experiments 1-4.

Stimuli and Procedure. Figure 10 shows an overview of one trial. In a practice block consisting of 192 trials, bar durations of $50,67,83$, and $100 \mathrm{msec}$ were presented in equal numbers. Half the trials had an orthogonally oriented bar, while the remainder had uniformly oriented bars, and the subjects were told this. Immediately following the bars was a $100-\mathrm{msec}$ white-noise mask consisting of checks equal in size to the bar width, with check luminances of $90 \mathrm{~cd} / \mathrm{m}^{2}$ and $4 \mathrm{~cd} / \mathrm{m}^{2}$. The masked region completely covered the region occupied by the oriented bars. Following the 


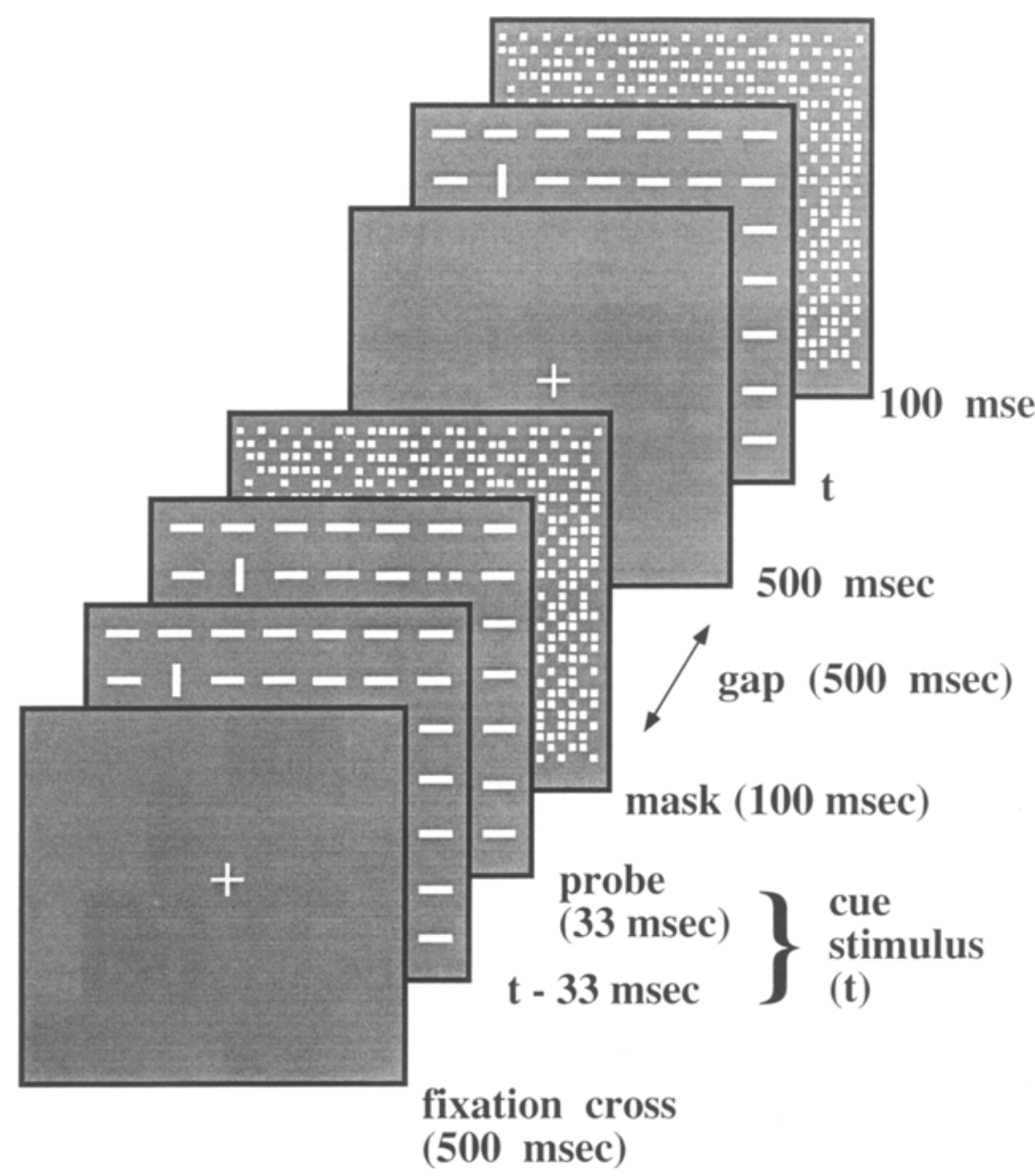

Figure 8. Overview of a trial in Experiment 4. Each trial consisted of two stimulus sequences, separated by a 500-msec blank gap, which were identical except that one contained the target (contained in the first sequence in the example depicted). The fixation cross appeared alone for $\mathbf{5 0 0} \mathbf{m s e c}$ and remained throughout the sequence. The cue stimulus then appeared for a duration of either $\mathbf{5 0}$ or 100 msec. In the sequence containing the target, the last two videoframes of the cue stimulus presentation contained a square break in one of the oriented bars, with luminance equal to that of the background. This was immediately followed by a 100-msec white-noise mask. The subjects selected which sequence contained the target by pressing one of two buttons.

mask was an array of selection tokens consisting of square outlines centered at the bar positions. The subject had $2 \mathrm{sec}$ to press a button if he/she thought a distinctly oriented bar was present. If not, the subject was to wait the $2 \mathrm{sec}$, at which time the screen cleared to the background gray level. If the subject pressed the button during the 2-sec interval, the selection tokens stayed on the screen until the subject indicated one of the four possible locations with a mouse, at which time the screen cleared. A correct selection was indicated with a beep. The subjects could not initiate a trial for $2 \mathrm{sec}$ after completion of the preceding trial. Other display parameters were the same as those in Experiment 1. At the beginning of the session, the subjects were shown frozen versions of the bars with the oddball at each one of its four possible locations, as well as examples of uniformly oriented bars. If performance for 50msec bars in the practice session was above $70 \%$, the bar durations presented in the experiment were $33,50,67$, and $83 \mathrm{msec}$. Otherwise, the same bar durations used in the practice $(50,67,83$, and $100 \mathrm{msec}$ ) were used in the experiment.

The frames involved in each trial were as follows (Figure 10): (1) The fixation cross appeared alone for $500 \mathrm{msec}$, and remained until the end of the trial. (2) For S10-S14 only, the squares were presented for $1,000 \mathrm{msec}-t$, where $t$ is the duration of the oriented bars. (3) The oriented bars were presented for a time, $t$. (4) The white-noise mask was presented for $100 \mathrm{msec}$. (5) The array of selection tokens was presented until the button was pressed or until $2 \mathrm{sec}$ had passed.

S10-S18 and one author (J.S.J.), who participated in the attention experiments previously described, performed this task in one final session lasting approximately $70 \mathrm{~min}$. After the practice, each subject completed 448 trials. The trials were balanced for pop-out presence, background orientation, bar duration, and the location of the pop-out (if any), and they were randomly shuffled. For S15S18 and J.S.J., who participated in Experiments 2 and 3, no squares were presented before the bars in order to keep the stimulus as close as possible to what they had seen in the attention experiment.

\section{Results}

Figure 11 shows the results of the discrimination and localization experiment. For clarity, we have plotted only the fraction correct (about presence/absence of oddball) for the discrimination. The fraction of trials with correct 

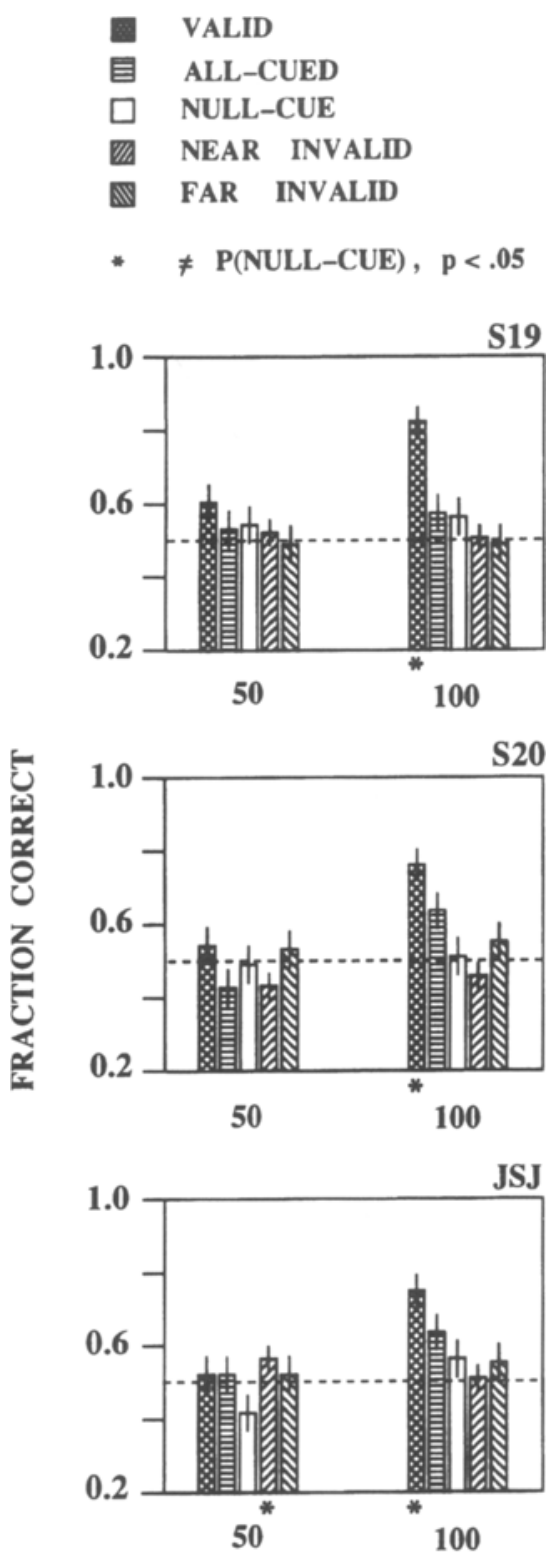

CUE STIMULUS DURATION (msec)

Figure 9. Results of Experiment 4. Both subjects showed significantly enhanced performance in trials with a valid pop-out relative to trials without pop-out with a 100-msec stimulus onset asynchrony (SOA) between the cue and the mask. For 100-msec cues, all 3 subjects also showed significantly greater accuracy in valid trials compared with all-cued trials (oddball at each of the four possible target locations). The target appeared on the last two videoframes of the cue stimulus.

responses for both the discrimination and the localization was never significantly different from this. The SOA required to perform the discrimination at the $75 \%$ correct level under these conditions was in the range of 50$70 \mathrm{msec}$. This is consistent with processing times in the range of 40-65 msec typically reported for orientation discrimination (Bergen \& Julesz, 1983). The orientation displays that have been used in the present research are therefore not unusual in this respect.

\section{DISCUSSION}

We conclude that orientation differences can cause shifts of visual attention, regardless of whether they convey any information relevant to the task at hand. This instance of a textural difference across space provides the first direct confirmation of the general hypothesis that texture gradients can cause involuntary shifts of visual attention. These attentional shifts can be observed with very brief SOAs between the orientation stimulus and the target mask; the experiments reported here show that a $100-\mathrm{msec}$ SOA is sufficient. The attentional facilitation that results from a noninformative orientation difference is transient, in many cases absent for a $250-\mathrm{msec}$ SOA. No facilitation was observed for an 800-msec SOA, and inhibition-of-return was observed in some cases.

These results have implications for the nature of the processing involved in rapid texture discrimination. With an SOA of only $100 \mathrm{msec}$, involuntary attentional shifts resulting from texture differences in the display have an effect on the processing of visual stimuli. In an orientation discrimination experiment, such as Experiment 5, visual attention is directed toward the oriented elements that are relevant to that task. By contrast, in experiments testing for involuntary attentional shifts due to orientation differences, the oriented elements are irrelevant to the task at hand, and so might not be processed quite as rapidly as they are in an orientation discrimination experiment. Conservatively, then, one should consider the 100 -msec SOA for which we observed effects of involuntary attentional shifts to be an upper bound on the minimum SOA required for such shifts to affect discrimination performance. At SOAs of $100 \mathrm{msec}$ or longer, the preattentive nature of orientation discrimination is vitiated by the involuntary attentional shifts that occur naturally as a result of orientation differences in the display. Such experiments might be said to be probing bottom-up processing, which includes both the conventional notion of preattentive vision and the involuntary attentional shifts that can follow from it.

The findings reported here are also consistent with the notion that threshold orientation discrimination does not involve reallocation of attentional resources. The SOA required for threshold discrimination of the orientations in our displays was measured to be in the range of 50-70 msec. These SOAs were too brief for an appreciable effect of attentional shifts on the observed performance. Up to threshold performance, then, the results are consistent with preattentive processing underlying orientation discrimination.

The only difficulty with the idea that orientation discrimination is "preattentive" comes from the results of Mack, Tang, Tuma, Kahn, and Rock (1992), who found that large orientation differences can go undetected under conditions of inattention. Apparently, orientation discrim- 


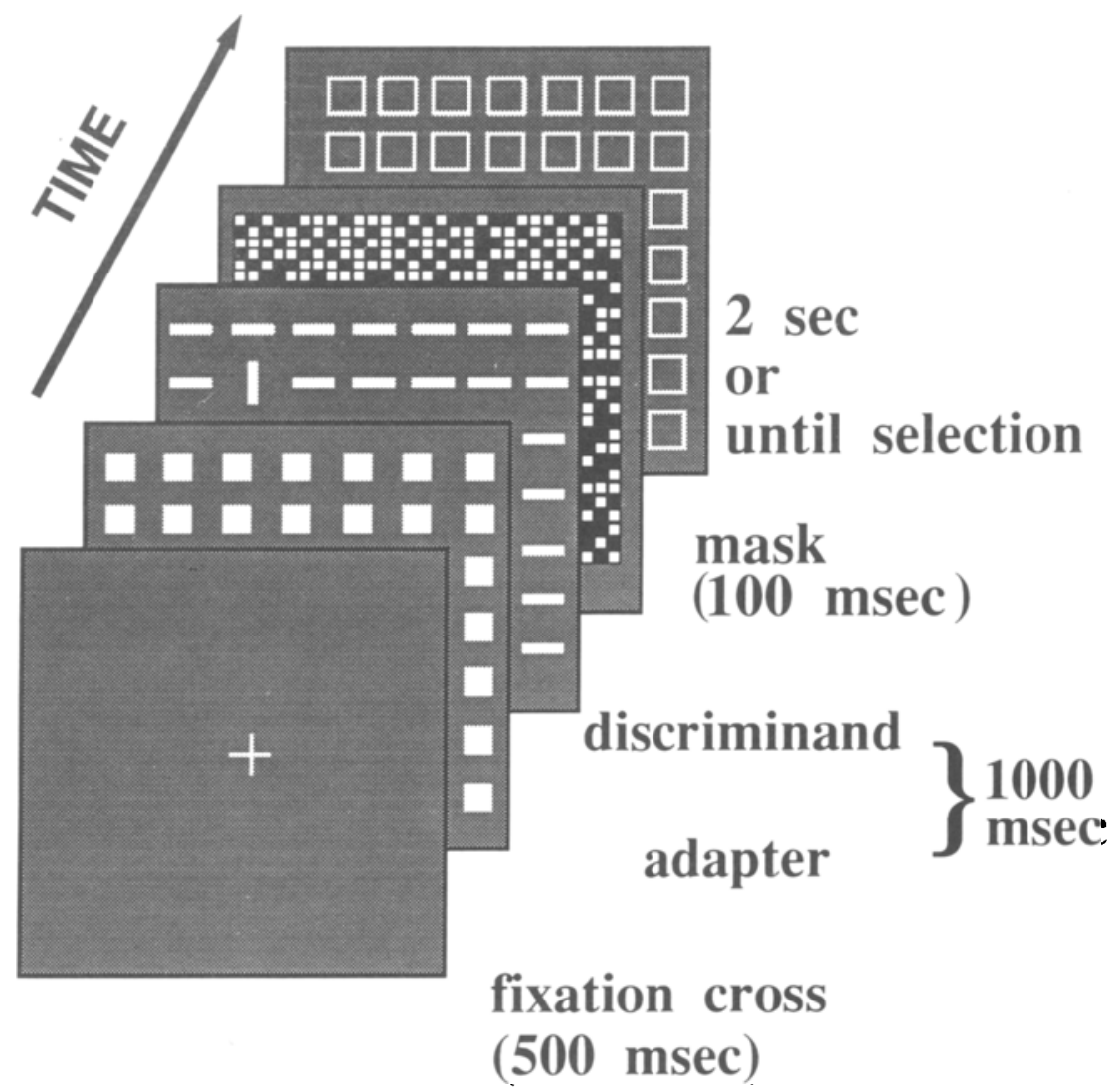

Figure 10. Overview of a trial in Experiment 5. To keep the stimuli as close as possible to what was presented in Experiments 1-3,S10-S14 were presented with squares before the oriented bars; S15-S18 and J.S.J. were not. The display of oriented bars (the discriminand) was presented for a randomly chosen time interval; for some subjects this ranged from 33 to $83 \mathrm{msec}$, while for others the range was 50-100 msec. This was immediately followed by a 100-msec white-noise mask and a display of selection tokens. These disappeared after $2 \mathrm{sec}$ if the subject wished to indicate that no oddball was present; otherwise they remained on display until a location was selected.

ination does require the allocation of some attentional resources, although the attentional load is light (Braun \& Sagi, 1991). This finding can easily be incorporated with our results, however. When resources are available for the detection of the orientation difference, the detected orientation difference causes an involuntary reallocation of the attentional resources.

We can conceive of several different pictures for the kind of signal that might be driving involuntary shifts of visual attention. Caelli's (1985) model of texture segmentation includes as its first stage the application of static nonlinear filters to the image input. An array of orientation-selective filters tuned to the pop-out orientation produces a strong output at the pop-out location, whereas the filters at other locations produce essentially no response. Considering this array as a processed image, this "neural image" contains luminance differences whereas the original image contained textural differences. These luminance differences might then be responsible for involuntary shifts of visual attention, similar to the cuing effects that have been observed in response to noninformative luminance flashes (Krose \&
Julesz, 1989; Maylor, 1985; Posner \& Cohen, 1984). In other words, after simple filtering, an orientation popout display becomes an (almost) abrupt onset. The texture segregation model of Bergen and Adelson (1988) produces an output that could be used in a similar fashion. Related to this is the possibility that attention is attracted to the outstanding perceptual group represented by a distinctly oriented bar against a background of otherwise like-oriented bars. An alternative perspective relates to the suggestion that texture segregation has access only to some kind of surface representation, and has no direct access to the output of an early filtering stage ( $\mathrm{He}$ \& Nakayama, 1994). At present we do not know whether it is a surface representation or an early filtering stage that provides the driving signal for involuntary attentional shifts. The data presented here are consistent with either alternative, and further experiments will be required in order to distinguish between these two possibilities.

The attentional shifts resulting from orientation differences potentially have important consequences for natural texture perception. The naturally occurring texture difference produced by an object against a background is 


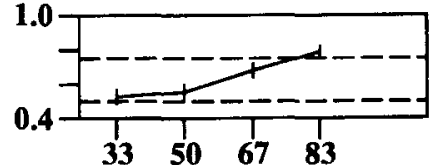

$\mathbf{S 1 0}$
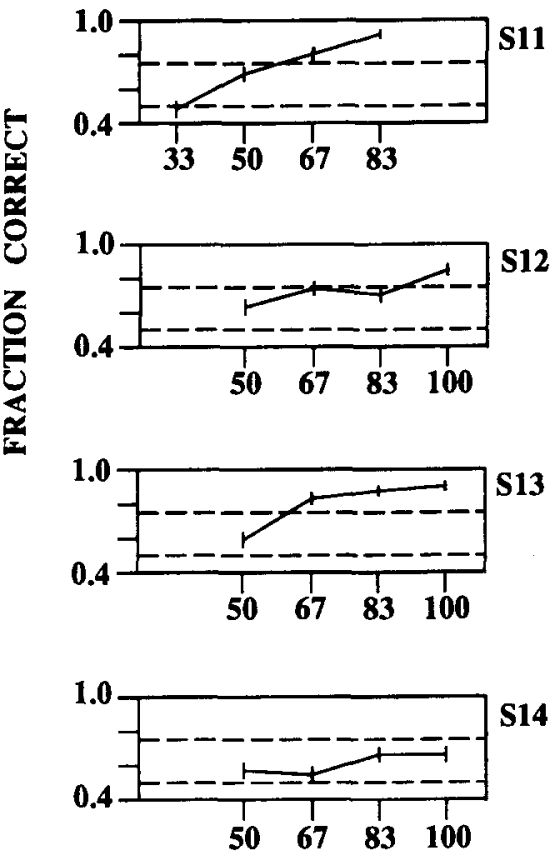

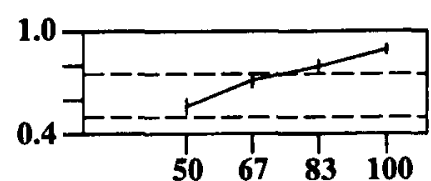

$\mathbf{S 1 5}$

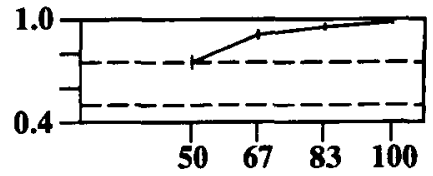

S16

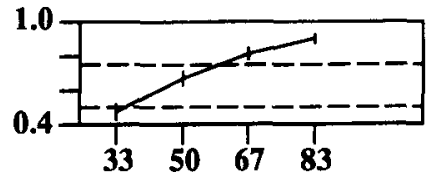

S17
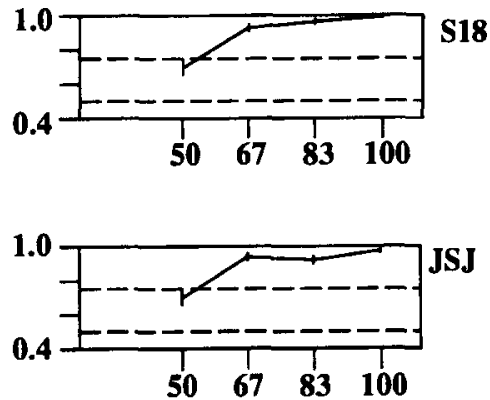

\title{
STIMULUS ONSET ASYNCHRONY (msec)
}

\begin{abstract}
Figure 11. Results of the rapid orientation discrimination experiment. Data points indicate the fraction correct for the discrimination without regard to localization performance. For clarity, the fractions correct in discrimination and localization together are not shown; they are nearly the same as for correct discrimination. The chance level for the discrimination (50\%) and the $75 \%$ level are indicated by dashed lines. Subjects typically required a 50- to 70-msec stimulus onset asynchrony (SOA) to achieve $75 \%$ correct discrimination under these conditions.
\end{abstract}

likely to contain not only an orientation difference but also differences of less salient textural properties. The perception of these less conspicuous properties would greatly benefit from the increased processing capacity associated with the attentional shifts.

A related set of issues is the neurophysiological basis of attentional shifts of the involuntary as well as the voluntary kind. This has been the subject of numerous investigations (see, e.g., Bushnell, Goldberg, \& Robinson, 1981; Colby, 1991; Goldberg \& Wurtz, 1972; Moran \& Desimone, 1985; Motter, 1993; Petersen, Robinson, \& Morris, 1987). Nakayama and Mackeben (1989) pointed out that it is possible in principle for involuntary attentional shifts to be mediated by an area as early as V1. Since then, orientation pop-out stimuli have been used to study macaque V1 neurons (Knierim \& Van Essen, 1992; Lamme, 1994), and cells have been found to be sensitive to the presence of orientation differences in the display. With multiple stimuli in the display, V1 responses can be influenced by the voluntary allocation of attention (Motter, 1993). Whether V1 responses are affected by the validity of an orientation difference that is noninformative for the task at hand remains to be seen.

\section{REFERENCES}

BaCON, W. F., \& EGETH, H. E. (1994). Overriding stimulus-driven attentional capture. Perception \& Psychophysics, 55, 485-496.

BECK, J. (1966). Effect of orientation and of shape similarity on perceptual grouping. Perception \& Psychophysics, 1, 300-302.

BERGEN, J. R., \& ADELSON, E. H. (1988). Visual texture segmentation and early vision. Nature, 333, 363-364.

BERGEN, J. R., \& JULESZ, B. (1983). Rapid discrimination of visual patterns. IEEE Transactions on Systems, Man, \& Cybernetics, 13, 857863.

BRAUn, J., \& SAGI, D. (1991). Texture-based tasks are little affected by second tasks requiring peripheral or central attentive fixation. Perception, 20, 483-500.

Brownlee, K. A. (1965). Statistical theory and methodology in science and engineering (2nd ed.). New York: Wiley.

Bushnell, M. C., GoldberG, M. E., \& Robinson, D. L. (1981). Be- 
havioral enhancement of visual responses in monkey cerebral cortex. I. Modulation in posterior parietal cortex related to selective visual attention. Journal of Neurophysiology, 46, 755-771.

CAElli, T. (1985). Three processing characteristics of visual texture segmentation. Spatial Vision, 1, 19-30.

CoLBY, C. L. (1991). The neuroanatomy and neurophysiology of attention. Journal of Child Neurology, 6, S90-S118.

ERIKSEN, C. W., \& ST. JAMES, J. D. (1986). Visual attention within and around the field of focal attention: A zoom lens model. Perception \& Psychophysics, 40, 225-240.

ERIKSEN, C. W., \& YeH, Y. (1985). Allocation of attention in the visual field. Journal of Experimental Psychology: Human Perception \& Performance, 11, 583-597.

FisCHER, B., \& BocH, R. (1983). Saccadic eye movements after extremely short reaction times in the monkey. Brain Research, 260, 21-26.

FISHER, R. A. (1935). The logic of inductive inference. Journal of the Royal Statistical Society, 98, 39-54.

Folk, C. L., Remington, R. W., \& Johnston, J. C. (1992). Involuntary covert orienting is contingent on attentional control settings. Journal of Experimental Psychology: Human Perception \& Performance, 18, 1030-1044

Folk, C. L., Remington, R. W., \& Johnston, J. C. (1993). Contingent attentional capture: A reply to Yantis (1993). Journal of Experimental Psychology: Human Perception \& Performance, 19, 682-685.

Folk, C. L., Remington, R. W., \& WRIGHT, J. H. (1994). The structure of attentional control: Contingent attentional capture by apparent motion, abrupt onset, and color. Journal of Experimental Psychology: Human Perception \& Performance, 20, 31 7-329.

GoldBERG, M. E., \& WurTZ, R. H. (1972). Activity of superior colliculus in behaving monkey. II. Effect of attention on neuronal responses. Journal of Neurophysiology, 35, 560-574.

He, Z., \& NaKaYama, K. (1994). Perceiving textures: Beyond filtering. Vision Research, 34, 151-162.

Hillstrom, A. P., \& Yantis, S. (1994). Visual motion and attentional capture. Perception \& Psychophysics, 55, 399-411.

Hubel, D. H., \& Wiesel, T. N. (1968). Receptive fields and functional architecture of monkey striate cortex. Joumal of Physiology, 195, 215-243.

JoNIDES, J., \& YANTIS, S. (1988). Uniqueness of abrupt visual onset in capturing attention. Perception \& Psychophysics, 43, 346-354.

JosePH, J. S., \& OPTICAN, L. M. (1993a). Involuntary shifts of visual attention caused by orientation gradients. Bulletin of the Psychonomic Society, 31, 367.

JoSEPH, J. S., \& OPTICAN, L. M. (1993b). Orientation pop-out as an exogenous cue for visual attention: Temporal and spatial properties [Abstract]. Investigative Ophthalmology \& Visual Science, 34 (Suppl.), 1235 .

JULESZ, B. (1984). Toward an axiomatic theory of preattentive vision. In G. M. Edelman, W. E. Gall, \& W. M. Cowan (Eds.), Dynamic aspects of neocortical function (pp. 585-612). New York: Neurosciences Research Foundation.

JuLESZ, B. (1986). Texton gradients: The texton theory revisited. Biological Cybernetics, 54, 245-251.

Julesz, B., \& Bergen, J. R. (1983). Textons, the fundamental elements in preattentive vision and perception of textures. Bell System Technical Journal, 62, 1619-1645.

Kahneman, D., \& Treisman, A. (1984). Changing views of attention and automaticity. In R. Parasuraman \& R. Davies (Eds.), Varieties of attention (pp. 29-61). New York: Academic Press.

Knierim, J. J., \& VAN Essen, D. C. (1992). Neuronal responses to static texture patterns in area V1 of the alert macaque monkey. Journal of Neurophysiology, 67, 961-980.

Koch, C., \& Ullman, S. (1985). Shifts in selective visual attention: Towards the underlying neural circuitry. Human Neurobiology, 4, 219-227.

Krose, B. J. A., \& Julesz, B. (1989). The control and speed of shifts of attention. Vision Research, 29, 1607-1619.

KWAK, H., \& EGETH, H. (1992). Consequences of allocating attention to locations and to other attributes. Perception \& Psychophysics, 51, 455-464.
LAMme, V. A. F. (1994). Neuronal correlates of figure-ground segregation in primary visual cortex [Abstract]. Investigative Ophthalmology \& Visual Science, 35 (Suppl.), 1489.

LANDY, M. S., \& BERGEN, J. R. (1991). Texture segregation and orientation gradient. Vision Research, 31, 679-691.

Luschow, A., \& NothdurFt, H. C. (1993). Pop-out of orientation but no pop-out of motion at isoluminance. Vision Research, 33, 91-104.

Mack, A., Tang, B., Tuma, R., Kahn, S., \& Rock, I. (1992). Perceptual organization and attention. Cognitive Psychology, 24, 475-501.

MAYLOR, E. A. (1985). Facilitatory and inhibitory components of orienting in visual space. In M. I. Posner \& O. S. M. Marin (Eds.), Attention and performance XI (pp. 189-204). Hillsdale, NJ: Erlbaum.

MiLLER, J. (1989). The control of attention by abrupt visual onsets and offsets. Perception \& Psychophysics, 45, 567-571.

Moran, J., \& Desimone, R. (1985). Selective attention gates visual processing in the extrastriate cortex. Science, 229, 782-784

MoTTER, B. (1993). Focal attention produces spatially selective processing in visual cortical areas $\mathrm{V} 1, \mathrm{~V} 2$, and $\mathrm{V} 4$ in the presence of competing stimuli. Journal of Neurophysiology, 70, 909-919.

Müller, H. J., \& RabBitT, P. M. A. (1989). Reflexive and voluntary orienting of visual attention: Time course of activation and resistance to interruption. Journal of Experimental Psychology: Human Perception \& Performance, 15, 315-330.

Nakayama, K., \& MaCkeben, M. (1989). Sustained and transient components of focal visual attention. Vision Research, 29, 1631-1647.

Nakayama, K., \& Silverman, G. H. (1986). Serial and parallel processing of visual feature conjunctions. Nature, 320, 264-265.

NeISSER, U. (1967). Cognitive psychology. New York: Apple-CenturyCrofts.

PASHLER, H. (1988). Cross-dimensional interaction and texture segregation. Perception \& Psychophysics, 43, 307-318.

Petersen, S. E., Robinson, D. L., \& Morris, J. D. (1987). Contributions of the pulvinar to visual spatial attention. Neuropsychologia, 25, 97-105.

Posner, M. I., \& Cohen, Y. (1984). Components of visual orienting. In H. Bouma \& D. G. Bouwhuis (Eds.), Attention and performance $X$ (pp. 531-556). Hillsdale, NJ: Erlbaum.

Remington, R. W., Johnston, J. C., \& Yantis, S. (1992). Involuntary attentional capture by abrupt onsets. Perception \& Psychophysics, 51, 279-290.

Sperling, G., \& Dosher, B. A. (1986). Strategy and optimization in human information processing. In K. R. Boff, L. Kauffmann, \& J. P. Thomas (Eds.), Handbook of human perception and performance (pp. 2-1 to 2-65). New York: Wiley

Theeuwes, J. (1991a). Cross-dimensional perceptual selectivity. Perception \& Psychophysics, 50, 184-193.

TheEuwes, J. (1991b). Exogenous and endogenous control of attention: The effect of visual onsets and offsets. Perception \& Psychophysics, 49, 83-90.

TheEuwes, J. (1992). Perceptual selectivity for color and form. Perception \& Psychophysics, 51, 599-606.

TheEuwes, J. (1994). Stimulus-driven capture and attentional set: Selective search for color and visual abrupt onsets. Journal of Experimental Psychology: Human Perception \& Performance, 20, 799-806.

TOCHER, K. D. (1950). Extension of the Neyman-Pearson theory of tests to discontinuous variates. Biometrika, 37, 130-144.

Treisman, A. M. (1985). Preattentive processing in vision. Computer Vision, Graphics, \& Image Processing, 31, 156-177.

Treisman, A. M., \& Gelade, G. (1980). A feature-integration theory of attention. Cognitive Psychology, 12, 97-136.

Weichselgartner, E., \& Sperling, G. (1987). Dynamics of automatic and controlled visual attention. Science, $\mathbf{2 3 8}, \mathbf{7 7 8 - 7 8 0 .}$

Wolfe, J. M., Cave, K. R., \& Franzel, S. L. (1989). Guided search model: An alternative to the feature integration model for visual search. Journal of Experimental Psychology: Human Perception \& Performance, 15, 419-433

YANTIS, S. (1993). Stimulus-driven attentional capture and attentional control settings. Journal of Experimental Psychology: Human Perception \& Performance, 19, 676-681. 
YANTIS, S., \& EGETH, H. E. (1994). Visual salience and stimulus-driven attentional capture [Abstract]. Investigative Ophthalmology \& Visual Science, 35 (Suppl.), 1619.

YANTIS, S., \& Hillstrom, A. P. (1994). Stimulus-driven attentional capture: Evidence from equiluminant visual objects. Journal of Experimental Psychology: Human Perception \& Performance, 20, 95-107.

YANTIS, S., \& JoNIDES, J. (1984). Abrupt visual onsets and selective attention: Evidence from visual search. Journal of Experimental Psychology: Human Perception \& Performance, 10, 601-621.

YANTIS, S., \& JoNIDES, J. (1990). Abrupt visual onsets and selective attention: Voluntary versus automatic allocation. Journal of Experimental Psychology: Human Perception \& Performance, 16, 121-134.

\section{NOTE}

1. The Fisher test is conservative in that it is slightly biased in favor of not rejecting the null hypothesis that the means are equal. Thus, the Type I error probability for each comparison is less than the value quoted. Tocher (1950) showed that the introduction of a randomization procedure for borderline cases corrects this bias and produces a slightly more powerful test. We avoided this randomization, however, by choosing to discuss borderline cases individually.

(Manuscript received February 17, 1995; revision accepted for publication August 10,1995.) 